\title{
As funções da pena: uma breve análise das teorias existentes
}

\section{The functions of the penalty: a brief analysis of existing theories}

Las características de la pluma: un breve análisis de las teorías existentes

Guilherme De Paula Meiado ${ }^{1}$ Juliano Napoleão Barros ${ }^{2}$

${ }^{1}$ Bacharel em Direito pelo Centro Universitário Católico Salesiano Auxilium (UniSALESIANO), Lins, SP. Discente do programa de especialização "O Novo Código de Processo Civil" da Universidade de Marília (UNIMAR). E-mail: gpmeiado@gmail.com

${ }^{2}$ Mestre e Doutor em Direito pela Universidade Federal de Minas Gerais (UFMG). Professor do curso de Direito do Centro Universitário Católico Salesiano Auxilium (UniSALESIANO), Lins, SP. Professor do Programa de Mestrado em Direito do Centro Universitário Eurípedes de Marília (UNIVEM).E-mail: emaildojuliano@gmail.com 
Resumo: O presente artigo dedicou-se a investigar as Funções da Pena e sua eficácia no campo penal brasileiro diante da evolução do crime e suas punições. Para tanto, ocupou-se dos conceitos e entendimentos de cada uma das teorias que envolvem as Funções da Pena, utilizando-se os fatores que podem levar uma pessoa a delinquir, descritos através dos pontos de vista sociológicos, filosóficos e psicológicos. Ao final, a pesquisa se dedicou a problematizar a teoria que o sistema brasileiro adota, observando se esta atende às necessidades que o sistema carcerário brasileiro vive atualmente, apresentando brevemente uma resposta ao problema da falta de ressocialização.

Palavras-chave: funções da pena; Sistema Penal Brasileiro; desvio de conduta.

Abstract: The present article was dedicated to investigate the Functions of the Pena and its effectiveness in the Brazilian penal field before the evolution of the crime and its punishments. In order to do so, he dealt with the concepts and understandings of each of the theories that involve the Functions of Pena, using the factors that can lead a person to commit crime, described from the sociological, philosophical and psychological points of view. In the end, the research was dedicated to problematize the theory that the Brazilian system adopts, observing if it meets the needs that the Brazilian prison system currently lives, briefly presenting an answer to the problem of the lack of resocialization.

Key words: functions of the penalty; Brazilian Penal System; misconduct.

Resumen: Este artículo se dedica a investigar las funciones de las oraciones y su eficacia en el ámbito penal brasileña antes de la evolución de la delincuencia y su castigo. Por lo tanto, él levantó los conceptos e interpretaciones de cada una de las teorías que implican funciones de la pluma, el uso de los factores que pueden llevar a una persona a cometer un delito descrito por el punto de vista filosófico y psicológico sociológico. Al final, la investigación se dedica a cuestionar la teoría de que el sistema brasileño adopta, señalando si se ajusta a las necesidades del sistema penitenciario de Brasil vive actualmente, una breve presentación de una respuesta al problema de la reinserción social.

Palabras clave: funciones de la pluma; Sistema Penal Brasileño; mala conducta. 


\section{INTRODUÇÃO}

Como forma de controle social pós-transgressões legislativas, surge a penalização. Ao longo da história, o modo de aplicação da pena variou conforme as culturas. Para os tempos modernos, a pena possui funções sociais que devem ser atendidas para sua efetiva aplicação.

Para se entender o motivo pelo qual surgem as transgressões legislativas, é necessário que se analise o comportamento anômico, que corresponde à desorganização pessoal que leva o indivíduo a desrespeitar as normas sociais, ou seja, é o desvio de comportamento.

O desvio de comportamento se dá por meio da frustração do indivíduo, que percebe o crescimento de seus semelhantes e o seu detrimento, tornando-os ferramentas especiais para o Estado e sua organização, ao mesmo tempo em que ele se vê esquecido por não alcançar o mesmo grau de especialização.

A especialização pode ser compreendida pelos atributos que o indivíduo desenvolve, tornando a sua atividade necessária para o funcionamento do Estado, ou seja, é a importância - e, por consequência, o interesse do Estado - que o indivíduo desenvolve.

Ocorrendo a especialização, perde-se o conhecimento compartilhado, uma vez que a sociedade precisa dividir suas funções, fazendo com que o senso de coletividade se desintegre, isolando os indivíduos não especializados dos demais.

Para essa corrente, o desvio de comportamento se dá pela falta de oportunidades culturais e sociais do indivíduo, pois a sociedade cobra que ele desenvolva suas habilidades e se torne uma ferramenta importante na organização social, porém, por não possuir acesso aos meios, ele não se desenvolve e acaba por ser negligenciado pelos demais.

Apesar de apresentar causas diferentes, é notório que ambas as teorias apontam como causa do desvio de conduta a obrigação de busca por metas e a exclusão social. 
É possível notar que a maioria dos detentos no Brasil hoje provém de classes caracterizadas pela não especialização dos indivíduos (SARDINHA; COELHO, 2014), que não tiveram ao seu alcance subsídios para o seu desenvolvimento pessoal e profissional, ou qualquer tipo de incentivo de crescimento, podendo fazer com que o ambiente no qual estavam inseridos ajudasse no desenvolvimento de sua personalidade.

Assim, seguindo a lógica descrita acima, se um indivíduo se desenvolve em um ambiente violento, sem cuidados Estatais e sem qualquer perspectiva de vida, que é o ambiente encontrado em grande parte das periferias brasileiras, ele pode assumir para si esse estilo e desenvolver características com o que vivenciou.

Entretanto existe o desvio de conduta em classes sociais mais favorecidas, o que pode ser explicado pela teoria de Merton e os diversos tipos de comportamento, que não são objeto desta pesquisa, pois não se busca compreender todas as causas que levam uma pessoa a delinquir, mas sim apresentar um breve panorama para que se entendam os modos adotados pelo Estado no funcionamento do Sistema de Justiça.

Ocorrendo o desvio de conduta, surgem as infrações legislativas, tendo o Estado o papel de responder a tais infrações. Da necessidade de resposta em face das infrações das regras de convívio social, surgem as penas.

Inicialmente serviam para castigar os infratores, mas, com o decorrer dos anos, elas adquiriram o sentido de "cuidado" com o infrator e sociedade, ou seja, não é mais apenas uma punição, mas sim uma prevenção e forma de reinserir o infrator na comunidade.

As penas podem ser corporal, privativa de liberdade, restritiva de liberdade, pecuniária e privativa de direitos. Na legislação penal, adotam-se de forma ampla, as penas privativas de liberdade.

Criada para reinserir o condenado ao convívio social, dando-lhe condições necessárias para não voltar a reincidir, as penas privativas 
de liberdade demonstram que, sem preparo estatal, elas não desenvolvem seu caráter ressocializador, mas tornam-se, talvez, semeIhante aos sistemas antigos, em que apenas castiga-se o condenado, deixando-o marcado perante a sociedade.

É vero que, para as penas privativas de liberdade alcançarem o ideal para o qual foram criadas, é necessário que o Estado ofereça condições físicas, mentais e cidadãs de ressocialização.

Neste sentido, pode-se entender que o que norteia os Estados nas aplicações das punições são as chamadas funções da pena Essas funções apontam os objetivos aos quais a pena deve alcançar para se demonstrar satisfatória para sociedade e o condenado.

Por meio da análise das funções da pena, surgem a teoria de suas aplicações e finalidades, existindo a teoria absolutista, a teoria relativa e a teoria mista, que são o objeto de estudo desta pesquisa.

\section{TEORIA ABSOLUTISTA}

Como uma forma de aplicar as penalidades, surgiu a Teoria Absolutista, desenvolvida na época em que o Estado e Igreja se confundiam quanto à criação e execução das leis, pois existia a concepção de um Juiz Divino, ou seja, com poderes atribuídos por Deus. Porém, com o avanço da sociedade, o intervencionismo perde força, e as leis humanas se sobrepõem às leis divinas, passando o Estado a ser o único a ditar as leis de convivência e aplicar as penas.

As absolutas fundam-se numa exigência de justiça: pune-se porque cometeu crime (punitir quia peccatum est). Negam elas fins utilitários à pena, que se explica plenamente pela retribuição jurídica. Ela é simples consequência do delito: é o mal justo oposto ao mal injusto do crime. (NORONHA, 2009, p. 223).

Assim, a teoria absolutista (ou retribucionista) da pena apresenta o dever do Estado em retribuir o mal cometido à sociedade, ou seja, 
punir o infrator na mesma proporcionalidade de seu crime. A pena torna-se meramente retributiva, desvinculando-a de seu efeito social, pois o único desejo é o de realização da justiça.

Nesse sentido, Moraes ([201-]) leciona:

Assim, as teorias retribucionistas consideravam tão-somente a expressão retribucionista da pena. Vale dizer, a pena traduzia um mal que recai sobre um sujeito que cometeu um mal do ponto de vista do direito. Essa concepção de pena estava ligada, sem quaisquer dúvidas, a uma visão de Estado guardião e não a um Estado intervencionista.

A pena consubstancia retribuição da culpabilidade do sujeito, considerada a culpabilidade como decorrente da idéia kantiana de livre arbítrio. Esse é seu único fundamento e, com amparo nesse argumento, é que se diz que, se o Estado não mais se ocupasse em retribuir, materializar numa pena a censurabilidade social de uma conduta, o próprio povo que o justifica também se tornaria cúmplice ou conivente com tal prática e a censura também sobre o povo recairia. (SUXBERGER, 2006 apud MORAES, [201-]).

Questiona-se a eficácia de tal teoria, uma vez que, dependendo de quão grave for considerado o delito, o condenado pode vir a sofrer penas desumanas, impossibilitando que tire dessa situação um ensinamento, voltando-se aos tempos em que os próprios cidadãos praticavam a "justiça" através da vingança, só que desta vez é o Estado que figura no polo ativo e não os senhores de terras.

Trata-se de uma perspectiva que se sustentava singularmente à luz do Estado de Polícia, quando os ditames absolutistas vinculavam os poderes do monarca a uma oblação divina - fato que, malgrado exercesse o papel de freio social, findava por garantir a existência de penas cruéis, desarrazoadas e dissociadas de um verdadeiro critério científico. Retrata-se, pois, o papel vingativo do Estado, desvinculado das preocupações com o futuro do apenado, tornando-se, por isso, insuficiente para 
as expectativas do Estado Democrático de Direito. (RIBEIRO; FREIRE, 2011, p. 150).

Observa-se que é visado apenas o momento do crime, ou seja, apenas a sua retribuição, sendo deixados de lado os eventos que se darão após o condenado voltar para a sociedade. A respeito dos efeitos de tal teoria, Montesquieu apresenta que:

Muitas vezes, um legislador que quer corrigir um mal só pensa nessa correção; seus olhos estão abertos para esse objetivo e fechados para os inconvenientes. Uma vez corrigido o mal, não se percebe mais a dureza do legislador, mas fica um vício no Estado, que esta dureza produziu; os espíritos estão corrompidos, acostumaram-se com o despotismo. (MONTESQUIEU, 2005, p. 96).

Desse pensamento, tira-se a conclusão de que a aplicação da pena dura e por si só aparenta corrigir o mal realizado, mas na verdade se apresenta como um evento propagador da reincidência, pois, como explanado por Montesquieu, o condenado terá se acostumado às penas duras e não terá medo de voltar a cometer outros crimes, pois não houve qualquer tipo de preocupação com o momento de seu retorno ao convívio social.

[...] um soldado, acostumado a expor sua vida todos os dias, despreza, ou vangloria-se de desprezar, o perigo. Ele foi acostumado a temer todos os dias a vergonha: era, então, necessário criar uma pena que o fizesse trazer uma ferida pelo resto da vida. Pensaram que estavam aumentando a pena, na realidade ela foi diminuída. Não se devem conduzir os homens pelas vias extremas: devem-se proteger os meios que a natureza nos dá para conduzi-los. (MONTESQUIEU, 2005, p. 95).

O que se observa nas periferias, que são os lugares abandonados pelo Estado e onde o crime se torna a única chance de sobrevivência, é que, por estarem desmotivadas e não possuírem um projeto de vida, as pessoas que vivem nessas zonas não possuem medo de sofrer punições, mas sim o medo de viver sofrendo com os sentimentos internos. 
Ou seja, o delinquente comete um crime porque não consegue viver sabendo que não pode ter um aparelho de última geração, ou não ter dinheiro para comprar alimentos ostentados pelas classes mais altas ou, ainda, com a ira com o seu semelhante. Esses sentimentos são mais fortes que o medo da sanção penal.

O Direito Penal não possui características vingativas, mas sim de proteção de bens jurídicos, tornando-se inconcebível a aplicação de tal teoria, pois ela não visualiza a ressocialização do indivíduo, tratando-o como mero instrumento a ser punido.

\section{TEORIA RELATIVA}

Com o passar dos anos, foi se atribuindo à pena o papel preventivo, pensando-se na reincidência do condenado e que a sociedade não venha a delinquir também. Aqui o mais importante não é a punição com a mesma proporcionalidade do crime, mas sim, a punição de forma exemplar, mostrando o poderio do Estado.

As teorias preventivas da pena destacam-se por não compartilharem do intuito de retribuir o fato delitivo cometido, de modo que não atribuem à pena, taxativamente, a incumbência de realizar justiça, mas de prevenir a prática de violações às normas do Direito Penal. (RIBEIRO; FREIRE, 2011, p. 151).

As teorias relativas procuram um fim utilitário para a punição. O delito não é causa da pena, mas ocasião para que seja aplicada. Não repousa na idéia de justiça, mas de necessidade social (punitir ne peccetur). Deve ela dirigir-se não só ao que delinquiu, mas advertir aos delinquentes em potência que não cometem crime. (NORONHA, 2009, p. 223).

Apesar de sua aparente preocupação social com a inibição da prática de novas violações às leis, é claramente utilizado o medo como principal instrumento de controle estatal. 
A tese preventiva tem por base a função de inibir o máximo possível a realização de novos atos ilícitos. A punição era encarada como meio de segurança e defesa da sociedade. Deste modo, a pena seria aplicada para impor o medo. Todavia, muitas vezes, tal medo era incapaz de coagir a prática do delito, já que o condenado agia com confiança de que não seria descoberto. (MORAES, [201-]).

O Estado utiliza-se do medo pelo grande poder transformador que este possui no caráter humano. Ou seja, passa-se a ideia de um Poder que deve ser temido, pois quem o desobedece, sofre pesadas consequências.

A finalidade para a qual foi criada a teoria da prevenção atinge tanto o apenado, quanto toda a sociedade, como apresentado anteriormente. Nesse sentido, encontra-se o posicionamento de Beccaria (2011, p. 58-9), em que possível se extrair o seguinte pensamento:

Os castigos têm por fim único impedir o culpado de ser nocivo futuramente à sociedade e desviar seus concidadão da senda do crime. Entre as penas e na maneira de aplicá-las proporcionalmente aos delitos, é mister, pois, escolher os meios que devem causar no espírito público a impressão mais eficaz e mais durável, e, ao mesmo tempo, menos cruel no corpo do culpado.

E Beccaria (2011, p. 59-60) ainda continua:

Quanto mais atrozes forem os castigos, tanto mais audacioso será o culpado para evitá-los. [...] Para que o castigo produza o efeito que dele se deve esperar, basta que o mal que causa ultrapasse o bem que o culpado retirou do crime.

Ainda sobre Beccaria (2011, p. 74) e continuando a relatar sobre o uso do medo, pode-se extrair seu seguinte pensamento: "não é o rigor do suplício que previne os crimes com mais segurança, mas a certeza do castigo [...]". 
Em outras palavras, Beccaria (2011) aponta que a finalidade da pena é flagelar o condenado de modo que impressione a sociedade, compelindo-a a não cometer os mesmos crimes.

Entretanto, apesar de se parecer uma excelente solução, a sua aplicação é falha.

A pena tem um fim prático e imediato de prevenção geral e especial do crime (punitur ne peccetur). A prevenção é especial porque a pena objetiva a readaptação e a segregação sociais do criminoso como meios de impedi-lo de voltar a delinquir. A prevenção geral é representada pela intimidação dirigida ao ambiente social (as pessoas não praticam o delito porque têm medo de receber punição). (BONFIM; CAPEZ, 2004, p.633).

Pode-se afirmar que a pena transpassa a pessoa do condenado, atingindo toda a sociedade, pois a crença de que, se a população tiver medo das penalizações, logo não irá cometer crimes, acaba subjugando a sociedade à vontade do Estado.

Confirmando o exposto acima, observa-se a descrição acerca de tal teoria realizada por Noronha (2004, p. 225):

As teorias relativas procuram um fim utilitário para a punição. O delito não é causa da pena, mas ocasião para que seja aplicada. Não repousa na idéia de justiça, mas de necessidade social (punitur ne peccetur). Deve ela dirigir-se não só ao que delinqüiu, mas advertir aos delinqüentes em potencial que não cometam crime. Consequentemente, possui um fim que é a prevenção geral e a particular.

Isso acaba por prejudicar a dignidade e a liberdade de cada membro da sociedade, pois vivem infelizes sob uma espécie de censura, temendo que sejam flagelados caso não sigam a vontade do Estado.

A utilização do medo como forma de controle social aterroriza toda a sociedade, coagindo a não cometer crimes pelos motivos errados, quando a sociedade deveria ser conscientizada da moral e bons costumes. Montesquieu (2005, p. 94) apresenta que "o povo romano 
tinha probidade. Esta probidade teve tanta força que, muitas vezes, o legislador só precisou mostrar-lhe o bem para fazê-lo seguir. Parecia que, no lugar de ordens, era suficiente dar-lhes conselhos".

Interpretando o disposto acima, deve o Estado controlar a sociedade através de normas de conduta preventivas, mas que não a amedronte. É essa a finalidade do Direito, é para isso que existem as normas, conforme aponta Cavalieri Filho (2010, p. 33-4):

O conflito gera o litígio, e este, por sua vez, quebra o equilíbrio e a paz social. A sociedade não tolera o estado litigioso porque necessita de ordem, tranquilidade, equilíbrio em suas relações. Por isso, tudo faz para evitar ou prevenir o conflito, e aí está a primeira função social do Direito - prevenir conflitos: evitar, tanto quanto possível, a colisão de interesses. Muita gente acredita que o Direito tem um caráter essencialmente repressivo, mas na realidade assim não é. [...] O Direito previne conflitos através de um conveniente disciplinamento social, estabelecendo regras de conduta na sociedade: direitos e deveres para locador e locatário, vendedor e comprador, enfim, para todos. À medida que cada um respeitar o disciplinamento estabelecido pelo Direito, evitará entrar em conflito com outrem na sociedade.

Desse modo, fica claro que o Direito não busca o controle social estabelecido no medo, mas sim por meio de ações que gerem ações positivas, a exemplo do respeito, as quais serão apreciadas pelo indivíduo que receber do Estado condições básicas que o ajudem a se tornar um ser humano capaz de compreender as normas sociais, deixando de lado a ideia de que é preciso temer, para respeitar.

\section{TEORIA MISTA}

Tentando balancear a pretensão punitiva com a pretensão preventiva, surge a teoria mista - ou unificadora - pois é notório o insucesso das teorias anteriores. Desse modo, tal teoria prega que o 
condenado deve sofrer pena equivalente ao mal causado - de modo mais brando -, mas que também deve servir de exemplo à sociedade.

No Estado moderno, junto a esta proteção de bens jurídicos previamente dados, surge a necessidade de assegurar, se necessário, através dos meios do direito penal, o cumprimento das prestações de caráter público de que depende o indivíduo no quadro da assistência social por parte do Estado. Com esta dupla função, o direito penal realiza uma das mais importantes das numerosas tarefas do Estado, na medida em que apenas a proteção dos bens jurídicos constitutivos da sociedade e a garantia das prestações públicas necessárias para a assistência possibilitam ao cidadão o livre desenvolvimento da sua personalidade, que a nossa Constituição considera como pressuposto digno. (ROXIN, 19--, p. 32 apud HIRECHE, 2004, p. 76, apud MORAES, [201-]).

Acredita-se que, com o condenado sofrendo penas capazes de marcá-lo eternamente e com essas marcas sendo vistas pela sociedade, a criminalidade diminuirá, pois o condenado, por medo, não reincidirá, e os possíveis novos criminosos, por medo, não cometerão crime. Buscando conceituar de forma doutrinária a finalidade da presente teoria, Noronha apresenta que:

[...] as teorias mistas conciliam as precedentes. A pena tem índole retributiva, porém objetiva os fins de reeducação do criminoso e de intimidação geral. Afirma, pois, o caráter de retribuição da pena, mas aceita sua função utilitária. [...] Cifra-se na prevenção geral e especial. A primeira dirige-se à sociedade, tem por escopo intimidar os propensos a delinquir, os que tangenciam o Código penal, os destruídos de freios inibitórios seguros, advertindo-os de não transgredirem o mínimo ético. Além dessa finalidade de caráter geral, há a especial. Com efeito, o delito é resultado de condições endógenas, próprias do criminoso, e exógenas, isto é, do meio circundante. [...] não se admite exclusivamente a sanção como retributiva - o mal da pena ao mal do crime - mas tem-se em vista a finalidade 
utilitária, que é a reeducação do indivíduo e sua recuperação. (NORONHA, 2009, p. 223-224).

Percebe-se ainda que a intenção de impressionar a população continua a ser o objetivo, além de se buscar uma punição com que faça o condenado sofrer a ponto de não voltar a delinquir.

A teoria unificadora de Claus Roxin vê o sentido da pena não apenas na compensação da culpa do delinquente, mas também no sentido geral de fazer prevalecer a ordem jurídica e também determinados fins político-criminais, com o fim de prevenir futuros crimes. Para esta teoria, o direito penal devia ser analisado sob o ponto de vista dos princípios constitucionais, notadamente aquele princípio constitucional considerado o norteador de toda e qualquer atuação num Estado democrático de direito, qual seja, o princípio da dignidade da pessoa humana. (MORAES, [201-]).

Através dessa busca da prevalência da ordem jurídica, a intenção é coibir futuros crimes, como já apresentado. Nesse sentido, Beccaria (2011, p. 59-61), exprime sua ideia da seguinte maneira:

Entre as penas e na maneira de aplicá-las proporcionalmente aos delitos, é mister, pois, escolher os meios que devem causar no espírito público a impressão mais eficaz e mais durável e, ao mesmo tempo, menos cruel no corpo do culpado. [...] o rigor das penas deve ser relativo ao estado atual da nação. São necessárias impressões fortes e sensíveis para impressionar o espírito grosseiro de um povo que sai do estado selvagem. Para abater o leão furioso, é necessário o raio, cujo ruído só faz irritá-lo. Mas, à medida que as almas se abrandam no estado de sociedade, o homem se torna mais sensível; e, se se quiser conservar as mesmas relações entre o objeto e a sensação, as penas devem ser menos rigorosas.

Lecionando sobre as condições da aplicação das penas, Foucault propaga o pensamento da punição severa e o medo que ela deve incutir, apresentando o seguinte pensamento: 
Pelo lado do condenado, a pena é uma mecânica dos sinais, dos interesses e da duração. Mas o culpado é apenas um dos alvos do castigo. Este interessa principalmente aos outros: todos os culpados possíveis. Que esses sinais-obstáculos que são pouco a pouco gravados na representação do condenado circulem então rápida e largamente; que sejam aceitos e redistribuídos por todos; que formem o discurso que cada um faz a todo mundo e com o qual todos se proíbem o crime - a boa moeda que, nos espíritos, toma o lugar do falso proveito do crime. (FOUCAULT, 1987, p. 90).

Entretanto é necessário observar-se o que foi discorrido nos itens anteriores, abordando a teoria absolutista e a relativa, quando foi apresentada a necessidade de o Estado controlar toda a sociedade através do medo, além de buscar aplicar ao condenado penas duras - e quase cruéis - para que este não volte a delinquir.

Colocando em foco as penitenciárias como principal modo de cumprimento da pena, Soares realiza uma ligação entre essa instituição e a teoria em foco, apresentando que:

[...] a prisão surge, essencialmente, como um meio de intimidação, pois, como notou Georg Rusche, tanto pior situação carcerária, mais intimidará o proletariado. "Se a vida dentro da prisão é igual ou melhor que a sua própria vida, a ameaça de prisão não surte efeito". (SOARES, 1986, p. 289).

Ocorre que as finalidades das teorias anteriores mostraram-se insuficientes para o controle da criminalidade na sociedade, então por que acreditar que uma teoria que reúne as duas anteriores será eficaz?

Do mesmo modo em que foi afirmado que a pena aplicada através da teoria relativa transpassa a pessoa do condenado, atingindo toda a sociedade, é essa a realidade na teoria agora estudada, uma vez que ela continua a seguir os mesmos princípios da anterior.

Tal posicionamento já fora explicado e amparado por Noronha, porém, é interessante que se apresente o pensamento de Soares, 
relacionando através do presente estudo, a aplicação da pena por essa teoria com a aplicação da pena nos modos primitivos:

Existe, por exemplo, a opinião muito generalizada, mas sem qualquer fundamento, segundo a qual a pena tem a origem no instinto de conservação individual, que se manifestaria como instinto de vingança, quando, na realidade, quem se vingava, nos mais recuados tempos, era o grupo a que pertencia o ofendido, vingança essa exercida não simplesmente contra o ofensor, mas contra o grupo do qual ele fazia parte, como forma de reação primitiva, entregue ao grupo. (SOARES, 1986, p. 281).

Nota-se que a pretensão de ressocialização ainda continua sendo fraca - na verdade inexistente. O mais importante é impedir que se cometam novos crimes e que se puna o criminoso na medida certa. O castigo é apresentado como a melhor forma de prevenção social.

O Estado continua a não notar que as mudanças efetivas na criminalidade se darão com investimentos maciços em áreas vitais para a sociedade, tais como educação, saúde e cultura. Além de tais investimentos, apresentar a ideia da recuperação daquele que delinquiu.

Esse fato remonta ao pensamento de Montesquieu já apresentado no presente trabalho, em que ele afirma que, quando o Estado transmite bons valores aos seus cidadãos, eles o copiarão, não existe a necessidade de punições.

Não é através de torturas, tratamentos desumanos e medo que se ensinará a população a respeitar as leis de convívio. Para isto existem outros meios, tais como uma educação de qualidade provida pelo Estado, além de oportunidades de desenvolvimento social, que não são o enfoque deste trabalho.

\section{CONCLUSÃO}

Observando-se todo o exposto, torna-se notório que o Estado Brasileiro utiliza-se da Teoria Mista, pois existe o endurecimento das 
punições, tornando-as cada vez mais severas, além da disseminação do medo quanto ao delito.

Isso ocorre, pois é muito mais fácil controlar uma sociedade envolta em medo e em uma falsa segurança, do que se buscar a diminuição da delinquência através de outras soluções e, também, buscar a recuperação do infrator.

A recuperação inclui esforços múltiplos do Estado e da sociedade que, algumas vezes, não se alinharam com os interesses políticos, uma vez que o discurso ao qual a população nos dias atuais se identifica é aquele voltado para punições mais rígidas.

No mesmo sentido, se dá a dificuldade de desenvolvimento de métodos que visam à diminuição da prática criminosa, pois não é o discurso de diminuição de violência que "vende", mas sim o de enrijecimento do sistema penal.

Se a sociedade percebesse que é possível, na maioria dos casos, recuperar o delinquente, trazendo-o de volta para o convívio em comunidade e, assim, diminuindo os altos índices de reincidência, certamente que ela teria aderido a programas ressocializadores.

Apesar de existir um discurso de ressocialização pelo Estado Brasileiro, a sua aplicação é prejudicada por conta da estrutura que possui hoje. Observa-se o pouco número de vagas em face ao grande número de detentos, aliado às péssimas condições físicas dos institutos prisionais e de seu regime que pouco faz pela reinserção social.

Para atingir a finalidade de reinserção social, talvez se faça necessária a aplicação de medidas alternativas, deixando de lado a tradicional imputação de penas, formando uma nova concepção de resposta à criminalidade.

Como forma de resposta, surgem estudos e correntes, a exemplo do Direito Penal Mínimo, que busca a não aplicação do Código Penal quando assim for possível, ou seja, devem entrar em cena as medidas 
alternativas de soluções de conflito para que a sociedade não fique refém das penas.

Pode-se compreender isso, pois continua sendo deixado de lado o aspecto restaurador das penalizações, fazendo com que, para toda e qualquer resolução de conflito, seja necessária a intervenção do Estado.

Para que o atual sistema funcionasse, far-se-ia necessária a união da pretensão de punir com a pretensão de ressocializar, rompendo com velhos paradigmas e reintegrando o infrator ao convívio comunitário, surgindo a "reparação".

A ideia de reparação abrange a sociedade, o condenado e a vítima, sem a necessidade da intervenção penal, quando a solução do conflito puder ser realizada sem ela. A essa reparação atribui-se o nome de Justiça Restaurativa, podendo ser definida como um caminho para a humanização do direito e uma resposta ao problema apresentado por este trabalho. O movimento restaurador vem crescendo pelo mundo todo, já sendo possível comparar as experiências ocorridas internacionalmente com uma possibilidade de aplicação na legislação brasileira.

\section{REFERÊNCIAS}

BECCARIA, Cesare. Dos delitos e das penas. Rio de Janeiro: Nova Fronteira, 2011. 146 p.

BONFIM, Edilson Mougenot; CAPEZ, Fernando. Direito Penal: parte geral. São Paulo: Saraiva, 2004. 897 p.

CAVALIERI FILHO, Sergio. Programa de Sociologia Jurídica. 12. ed. Rio de Janeiro: Forense, 2010.

FOUCAULT, Michel. Vigiar e punir: nascimento da prisão. Petrópolis, RJ: Vozes, 1987. 288 p.

MONTESQUIEU, Charles. Do espírito das leis. São Paulo: Martins Fontes, 2005. p. 93-104. 
MORAES, Henrique Viana Bandeira. Das funções da pena. Revista Âmbito Jurídico, Rio Grande, [201-]. Disponível em: <http://www.ambito-juridico. com.br/site/?n_link=revista_artigos_leitura\&artigo_id=12620>. Acesso em: out. 2015.

NORONHA, E. Magalhães. Direito Penal. 38. ed. São Paulo: Rideel, 2009. v. $1,381 \mathrm{p}$.

. Direito Penal: introdução e parte geral. 38. ed. São Paulo: Saraiva, 2004. v. 1. 388 p.

SARDINHA, Edson; COELHO, Mario. População carcerária cresce seis vezes mais em 22 anos. 2014. Disponível em: <http://congressoemfoco.uol.com. $\mathrm{br} /$ noticias/populacao-carceraria-cresce-seis-vezes-em-22-anos/>. Acesso em: mar. 2016.

SOARES, Orlando. Criminologia. Rio de Janeiro: Freitas Bastos, 1986.

RIBEIRO, Gabrielle Carvalho; FREIRE, Mariana Belchior Ribeiro. Funções da pena: paradoxos fáticos da teoria preventiva. ESMARN: Revista Direito e Liberdade, v. 13, n. 12, p. 147-70, jul./dez. 2011. 